\title{
Salt Rock Underground Gas Caverns Risk Assessment Based on Fuzzy
}

\author{
Math \\ Baoqun Wang*, Lili Tao, Bi He \\ School of Civil Engineerin, Shandong Jiaotong University, Jinan 250357, China \\ *29238767@qq.com
}

\begin{abstract}
Use salt rock underground caverns to store gas is an important storage mode in China, effective risk management is the key to the success of this method. Aimed to risk management, the foundation work is risk assessment. Fuzzy math is an effective method for solve uncertainty problem just like risk assessment. In this article, a salt rock underground gas caverns risk assessment model based Fuzzy Math was built, with this model, the risk level of salt rock underground gas caverns can be quantitatively evaluated, and the evaluation results can be used as a reference for risk rescue decision.
\end{abstract}

Keywords: Salt rock, Gas storage, Risk assessment, Fuzzy math

\section{Introduction}

Natural gas is becoming more and more important type of energy, according to statistics, it accounting for $25 \%$ of the global energy market, compared with the traditional forms of energy, such as coal, natural gas has the advantages of environmental protection and high efficiency. But, the storage of natural gas is a challenging problem, in many countries, such as China, many salt rock underground caverns were used to store natural gas, and then, the risk monitor and management became one problem. As the first step of risk management, risk assessment is an important problem, cause assessment results is the key accordance of risk rescue.

\section{Risk identification}

First step of risk assessment is risk sources identification. Through field surveying and analysis literature, the salt rock underground gas caverns accident type including three: caverns destroy, gas leakage, surface subsidence. And the cause of the accident comes from three aspects: geological conditions, design scheme, process equipment. According to this, risk factors table can be expressed as Table1:

Table 1 Risk factors table

\begin{tabular}{ccl}
\hline $\begin{array}{c}\text { Accident } \\
\text { Type }\end{array}$ & Aspects & \multicolumn{1}{c}{ Risk factors } \\
\hline & $\begin{array}{c}\text { geological } \\
\text { conditions } \\
\text { design }\end{array}$ & Low rock strength, rock creep, lots of rock \\
layers,large local temperature difference, etc & Pillar failure, small pillar space, roof flex,etc \\
caverns & scheme & \\
& process & Low gas pressure, pressure different, openration \\
& equipment & frequently, etc. \\
\hline
\end{tabular}




\begin{tabular}{|c|c|c|}
\hline \multirow{4}{*}{$\begin{array}{l}\text { gas } \\
\text { leakage }\end{array}$} & geological & Casting damage, binding surface slip, binding \\
\hline & $\begin{array}{l}\text { conaltions } \\
\text { design }\end{array}$ & $\begin{array}{l}\text { surface gap, etc. } \\
\text { Gas pressure high, low casting, equipment fatigue, }\end{array}$ \\
\hline & scheme & etc. \\
\hline & $\begin{array}{l}\text { process } \\
\text { equipment }\end{array}$ & $\begin{array}{l}\text { Valve damage, wellhead pressure improper, } \\
\text { equipment corrosion damage,ect. }\end{array}$ \\
\hline \multirow{3}{*}{$\begin{array}{c}\text { surface } \\
\text { subsidence }\end{array}$} & $\begin{array}{l}\text { geological } \\
\text { conditions }\end{array}$ & Thin top layer, rock creep, etc. \\
\hline & $\begin{array}{l}\text { design } \\
\text { scheme }\end{array}$ & Gas pressure low, roof flex, etc. \\
\hline & $\begin{array}{l}\text { process } \\
\text { equipment }\end{array}$ & Long time in low pressure, pressure different, etc. \\
\hline
\end{tabular}

After risk factors were collected, with the experts scoring method, the grade of every factor can be quantified, and risk identification was finished.

\section{Risk assessment based on Fuzzy Math}

After risk identification, the risk assessment model can be built, in this article, this model was built based on Fuzzy Math, concrete method is analytic hierarchy process. The first step of the model is build analytic hierarchy process diagram. According to the results of risk identification, three diagrams were created as Figure1, Figure2 and Figure3:

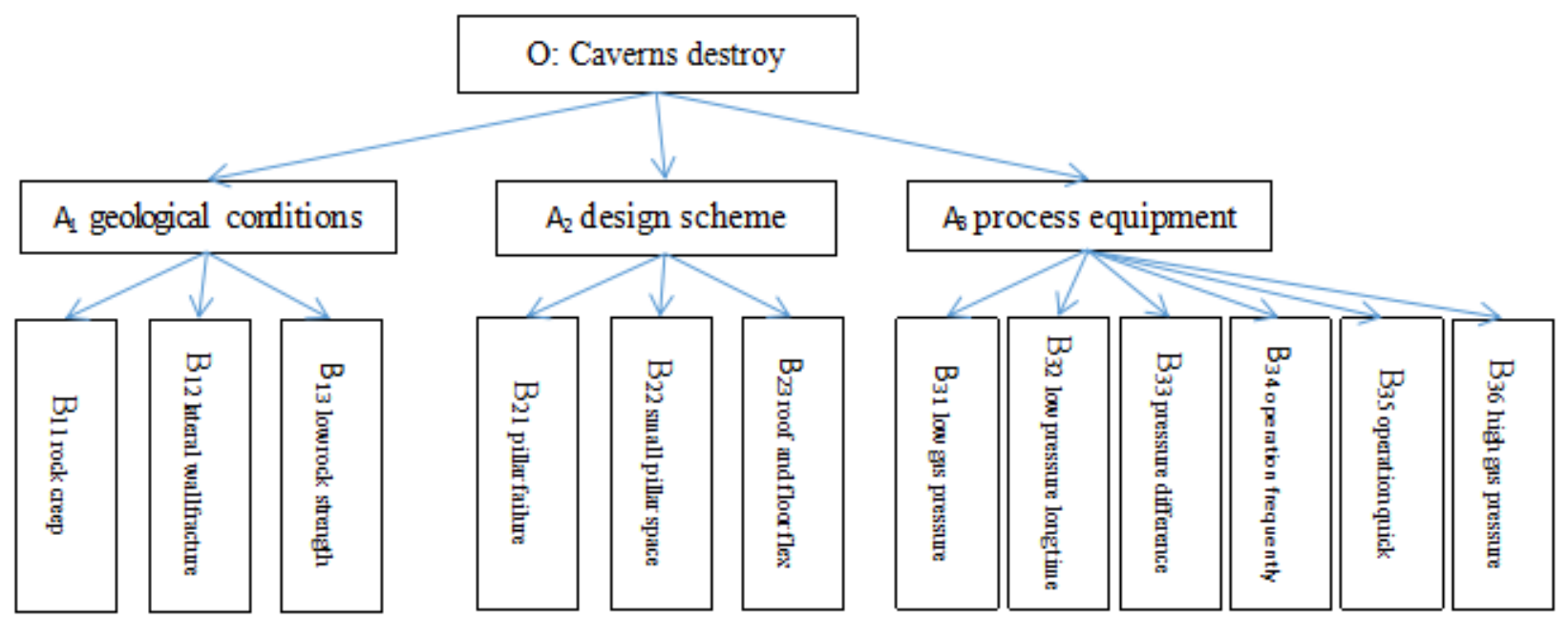

Fig.1 Analytic hierarchy diagram of caverns destroy 


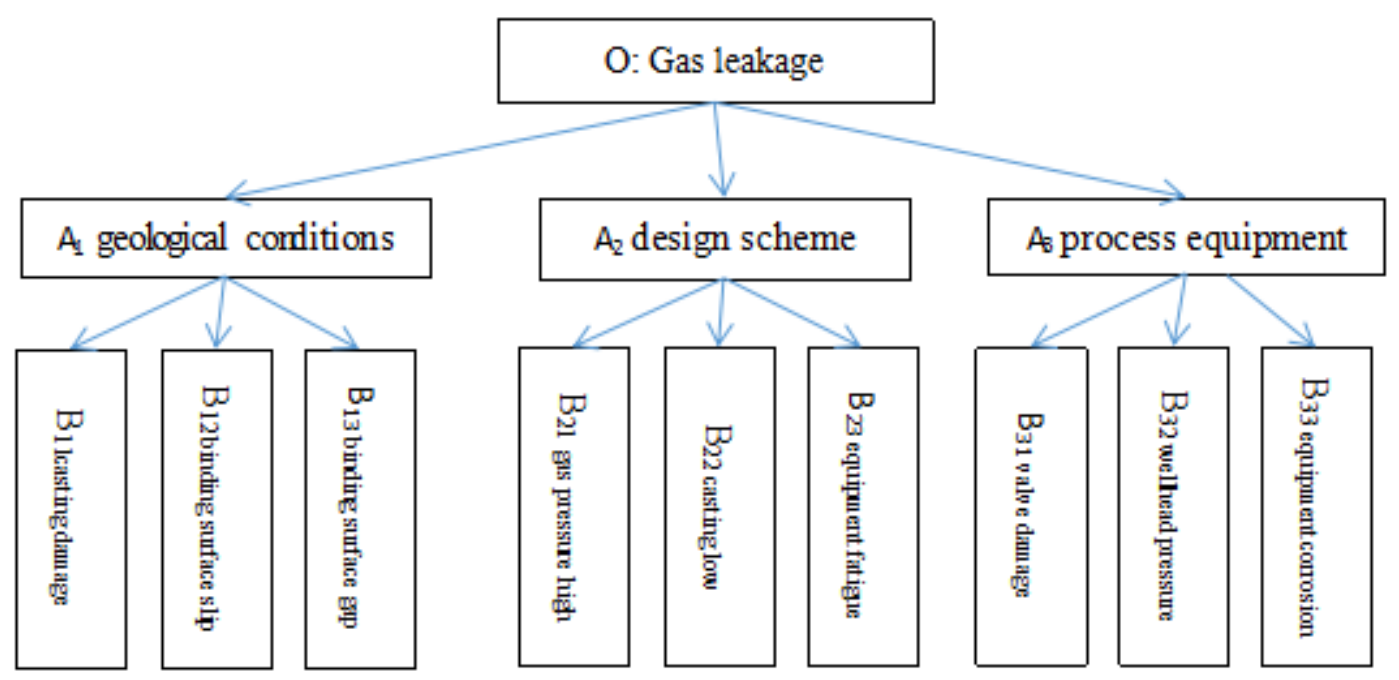

Fig.2 Analytic hierarchy diagram of gas leakage

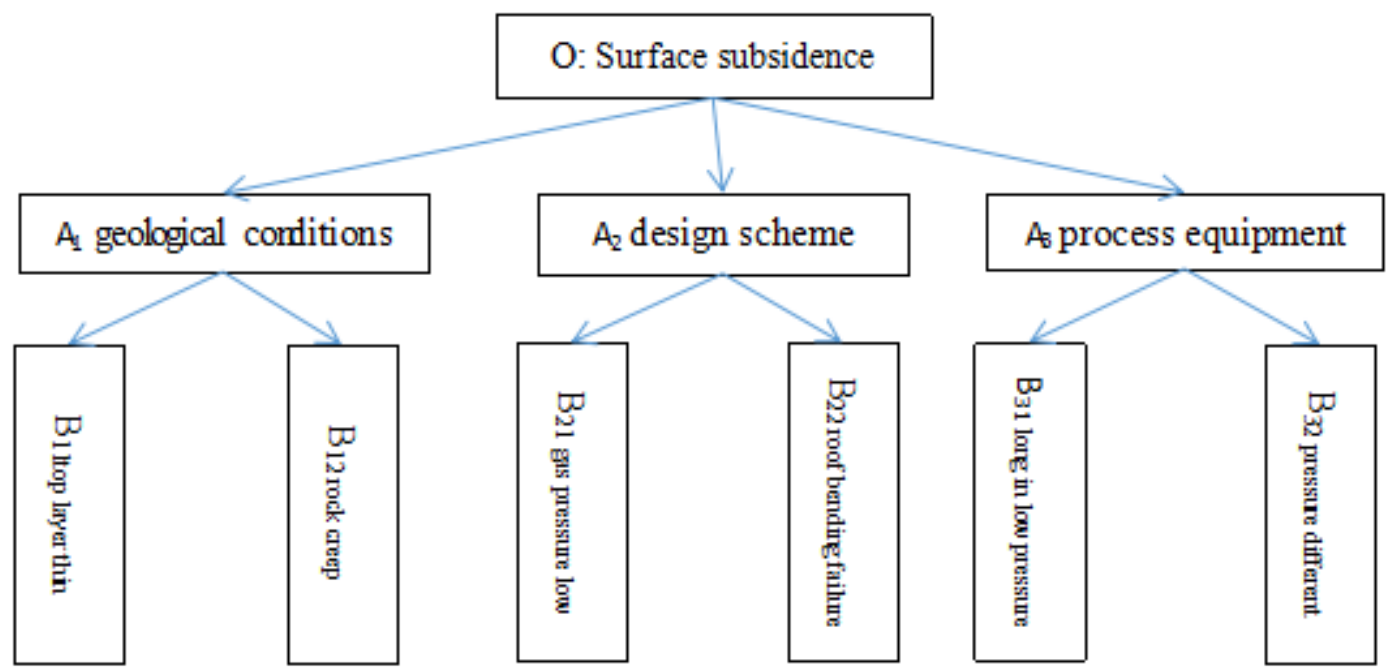

Fig.3 Analytic hierarchy diagram of surface subsidence

The second step of model is establish hierarchy judgment matrix.According to the analytic hierarchy diagram, set the up layer factor as standard, compared each two factors in lower layer effect to up layer factor, the results are expressed in digital form, so as to form a judgment matrix.

The third step of model is analytic hierarchy process calculation and consistency check. According to judgment matrix, calculate the low layer influence on up layer. And the consistency check is to verify whether the results of the level of consistency of the consistency of the results.

The last step of model is determination of risk level. The final calculated results of three risks are distributed between 0 to 1 . The risk level can be confirmed by the calculate results and Table2.

Table 2 Evaluation criterion of three risks

\begin{tabular}{ccc}
\hline Risk level & Index range & Risk state \\
\hline Very low risk & $(0,0.13)$ & Very low disk, can negligible \\
Low risk & {$[0.13,0.29)$} & Low risk, in acceptable range \\
Medium risk & {$[0.29,0.48)$} & Must pay attention \\
High risk & {$[0.48,0.71)$} & Need to take measures \\
Very high risk & {$[0.71,1)$} & Unacceptable \\
\hline
\end{tabular}




\section{Conclusion}

With the Fuzzy Math method, a risk assessment model for salt rock underground gas caverns can be built, use this model, after the steps of risk identification and risk assessment, the risk level can be quantitatively evaluated, and the evaluation results is the key for risk rescue decision. This work can greatly improve the scientific and accuracy of risk management level, reduce the loss of risk.

\section{Reference}

[1] Xue Yang, Stein Haugen. Risk information for operational decision-making in the offshore oil and gas industry[J].Safety Science, 2016 7. 98-109.

[2] Miguel Veiguela, Antonio Hurtado, Sonsoles Eguilior. A risk assessment tool applied to the study of shale gas resources[J]. Science of The Total Environment, 201610 (571) 551-560.

[3] M.R. Martins, M.A. Pestana, G.F.M. Souza, A.M. Schleder. Quantitative risk analysis of loading and offloading liquefied natural gas (LNG) on a floating storage and regasification unit (FSRU)[J]. Journal of Loss Prevention in the Process Industries, 20169 (43) 629-653.

[4]Ahmet Ozarsian. Large-scale hydrogen energy storage in salt caverns[J]. International Journal of Hydrogen Energy, 20127 (7) 1-3.

[5] Luisa Torres, Om Prakash Yadav, Eakalak Khan. A review on risk assessment techniques for hydraulic fracturing water and produced water management implemented in onshore unconventional oil and gas production[J]. Science of The Total Environment, 2016 1(539) 478-493.

[6] ZJiyao Gao, Fengqi You. Risk Management of Shale Gas Supply Chain under Estimated Ultimate Recovery Uncertainty[J]. Computer Aided Chemical Engineering, 2016 1(38) 529-534.

[7] Shuangcheng Zhang, Haiyang Cao, Han Gao, Haiying Li. Application and analysis of GPS Short Baseline Processing Based on GAMIT[J]. Survey and Mapping Bulletin, 2011(10) 27-29.

[8] Sangick Lee, Suwon Seo, Daejun Chang. Fire risk comparison of fuel gas supply systems for LNG fuelled ships[J]. Journal of Natural Gas Science and Engineering, 2015(19) 1788-1795.

[9] Xuan Zou, Weiming Tang, Chuang Shi, Jingnan Liu. Instantaneous Ambiguity Resolution For PPP-RTK Using Regional Ground-Based Augmentation Information[J], 2014 34(1) 78-83. 